\title{
Diagnosing Hypertension Among Adults; A Study Based on Prevention-Management of Primary and Secondary Hypertension
}

\author{
Mohamed Ombada ${ }^{1} \&$ Mulham Ombada ${ }^{2}$ \\ ${ }^{1}$ Wertheim Redcross Hospital, Orthopedic Surgical Resident, Wertheim, Germany \\ ${ }^{2}$ King AbdulAziz University Hospital, Jeddah, KSA \\ Correspondence: Mohamed Ombada, Wertheim Redcross Hospital, Orthopedic Surgical Resident, P.O Box Carl \\ Roth Street 3, Wertheim, 97877, Germany. E-mail: dr_mhabib@hotmail.com
}

Received: November 12, 2019 Accepted: Janaury 7, 2020 Online Published: Janaury 30, 2020

doi:10.5539/gjhs.v12n2p61

URL: https://doi.org/10.5539/gjhs.v12n2p61

\begin{abstract}
Hypertension is a great challenge for the public health professionals across the world, as it is a major risk factor leading to congestive heart failure, coronary heart disease, retinopathy, and renal disease. Therefore, the study aims to diagnose hypertension among the adults in Al-Riyadh district, Khartoum state of Sudan. The study investigated the prevention and management of primary and secondary hypertension. A cross sectional population-based study was conducted among 138 adult individuals aged between 16 and 75 years. The participants were selected using random sampling technique and each participant completed self-administered questionnaire to assess the prevention-management of primary and secondary hypertension. The mercury sphygmomanometer with standard cuff was used to take measurement of arterial blood pressure. The diagnosis of hypertension among the adults showed that its prevalence in the area of Riyadh was $28 \%$. The highest proportion of hypertension $(13.7 \%)$ was recorded among the patients aged from 45 and 60 years. There was significant association of age ( $p$-value $=0.001$ ), social status ( $p$-value $=0.001)$, stress $(p$-value $=0.010)$, and diabetes $(p$-value $=0.050)$ with hypertension. The present study has highlighted the significant factors associated with hypertension that encourages the public health professionals to carry out awareness and prevention programs.
\end{abstract}

Keywords: adults, cardiovascular diseases, diagnosis, hypertension, management, prevalence, prevention

\section{Introduction}

There is increased prevalence of hypertension across the world because it is a major public health challenge and cardiovascular risk factor leading to high rates of morbidity and mortality (van Kleef \& Spiering, 2017). There is significant association of increased risk of morbidity and mortality from the preventable complications with uncontrolled, undiagnosed, and inappropriate management of hypertension (Ogah et al., 2012; James et al., 2014; Ataklte et al., 2015). Increased blood pressure among the individuals is attributed to $58 \%$ of hemorrhagic stroke, $55 \%$ of ischemic disease, and 50\% of ischemic shock (Forouzanfar et al., 2017). Whereas, 58\% of cases attributed to increased blood pressure include cardiovascular diseases such as cardiomyopathy, peripheral vascular disease, rheumatic and hypertensive heart disease, and conduction disorders (Forouzanfar et al., 2017). It has been shown that there are 10.7 million deaths and 211.8 million daily adjusted life-years every year since the last decade (Forouzanfar et al., 2015). Hypertension remains highly prevalent and under recognized, despite of the mentioned statistics.

Increased blood pressure exerts excessive pressure on the artery walls that can cause severe damage to the blood vessels (Lurbe et al., 2016). The damage is greater, when increased blood pressure in left uncontrolled for a longer time period. Hypertension is diagnosed by taking measurements of blood pressure by making 3 different readings at three different times. The patient is prescribed medications, if all the three readings show increased blood pressure; whereas, the individual with just one elevated reading is advised preventive measures (Lurbe et al., 2016). There is significant impact of hypertension and its complications on the individuals, families, and health systems prevailing across different countries. The investigation of risks of uncontrolled hypertension in Sudanese showed that these patients were at higher risk of getting further complications (Sayers et al., 2009).

A study conducted by Babiker et al. (2013) used structured questionnaires to investigate the awareness and factors linked with the uncontrolled hypertension among the Sudanese adults. The results showed that prevalence of 
uncontrolled hypertension was increased among the male population (61\%), as compared to the females. The study showed strong association of family history of hypertension (54\%) and smoking habit $(52 \%)$. Other risk factor leading to hypertension include obesity (14).

Hypertension is not only a problem for the individuals, rather it is considered to have major social impact on the society because of its serious complications. The evidence obtained from clinical and epidemiological research has helped the physicians in selecting the best hypertension management strategies, considering the particular diagnostic or therapeutic means. The presence of guidelines for managing hypertension are not effective in managing the increasing burden of hypertension in Sudan. This is because of decreased awareness, poor control of blood pressure, poor treatment approaches, and increased burden of hypertension-related complications (Salako et al., 2007; Ogah et al., 2012; Ataklte et al., 2015). In the similar context, the present study aims to diagnose hypertension among the adults in Al-Riyadh district, Khartoum state of Sudan. Moreover, it would also identify the association of hypertension with different risk factors to formulate adequate prevention-management of primary and secondary hypertension.

\section{Literature Review}

Evidence from the literature identifies hypertension as a significant public health concern, given its increased prevalence across the world (Ahmed et al., 2014; Abebe et al., 2015; Lasisi, Abiona, \& Gureje, 2010; Mendis, 2010). Singh, Shankar, and Singh (2017) noted that hypertension accounts for 7.5 million deaths globally, as a result of increased blood pressure. Common causes of death due to hypertension include heart disease, strokes, and frequent renal failure. Tabrizi et al. (2016) predict that hypertension is likely to increase to 1.56 billion until 2025 in adults. The findings of Sarki et al. (2015) aligns with it, which demonstrates high blood pressure and hypertension in older individuals. A recent systematic review by Sarkari et al (2010) shows that hypertension was polled $2.5 \%$ more in adults above 65 years old as compared to 18 to 64 years. Adeloye \& Basquill (2014) epidemiological model depicted that hypertension was two to four times more prevalent among adults as compared to 40 years or younger. Duda et al. (2011) and Negin et al. (2011) have reported that adults need to identify the risk factors of hypertension for reducing its prevalence and overcoming its occurrence.

Dubey, Rastogib, and Awasthic (2019) stated that hypertension tends to prevail among those adults who were either on anti-hypertensive medication or frequently get their blood pressure measured. Similarly, Van Kleef and Spiering (2017) noted low awareness, suboptimal treatment, and inadequate control of hypertension leads to prevalence of hypertension. Such as Mills et al. (2016) indicates that globally, only 47 percent of the population has awareness concerning high $\mathrm{BP}$, which for high-income countries is 37 percent. It also highlights that despite the increase in the treatment, the prevalence continues to be high, which emphasizes instigating different programs for attaining improved results.

Tucker et al. (2017) meta-analysis report different diagnosis treatment for identifying the hypertension prevalence among adults. It demonstrates to integrate BP telemonitoring with different interventions, i.e., education or lifestyle counseling, or medication titration by a case manager, which assists to decline the rate of BP, in contrast to self-monitoring. Johnson et al. (2014) compared the new hypertension diagnosis rate for different age groups and for identifying the significant predictors that delay the initial diagnosis in young adults. It showed that different factors at both patient and practitioner levels lead to an inadequate diagnosis of hypertension. Fottrell et al. (2018) identified the non-communicable disease (NCD) risk factors, increased blood pressure, and hyperglycemia as immediate risk factors for hypertension in Bangladesh. Pinto and Martins (2017) have identified diabetes mellitus, arteriosclerosis, and metabolic syndrome, as major hypertension risk factors.

The prevalence of hypertension has increasingly been reported for the developed nations, such as in Portugal, hypertension had a prevalence rate higher than 40 percent among the adults (Oliveira-Martins et al., 2011; Pinto \& Martins, 2017). Similarly, Menéndez et al. (2016) found an increased prevalence of hypertension in adults in Spain, and Khader et al. (2019) in Jordan. However, no study has assessed the prevalence of hypertension among adults in Saudi Arabia. The present study bridges this gap by investigating the prevention and management of primary and secondary hypertension among adults in Saudi Arabia.

\section{Material and Methods}

The present study has employed descriptive cross-sectional community-based study in Al-Riyadh district that is situated in Khartoum East city. It is estimated that this region covers an area of $235,000 \mathrm{~m}^{3}$. The socioeconomic level of this region is considered moderate to high level. The participants for this study were recruited using simple random sampling. The target population for this study is the adult male and females $>16$ years and $<75$ years. The study excluded the individuals who were $<16$ years and $>75$ years of age. The time period in which the study took 
place was from March to April 2018.

Before conducting the interview, verbal consent was obtained from each participant, along with signature in the questionnaire paper in order to ensure confidentiality. The blood pressure measurements of all the individuals were taken using a stethoscope and a sphygmomanometer, while taking the interview. A structured survey using closed ended and categorized questionnaire was used to collect relevant significant information. The variables mainly focused on this study to assess the prevention and management of hypertension include; age, gender, marital status, level of education, and presence of primary or secondary hypertension. The data obtained through the questionnaire was entered, coded, and analyzed using Statistical Package of Social Sciences (SPSS) version 20.0.

\section{Results}

The study recruited 138 individuals to diagnose hypertension among the adults in Al-Riyadh district, Khartoum state of Sudan. Figure 1 has shown that $28 \%$ of the individuals were suffering from primary hypertension; whereas, $72 \%$ had developed hypertension as a secondary condition caused by another underlying medical condition.

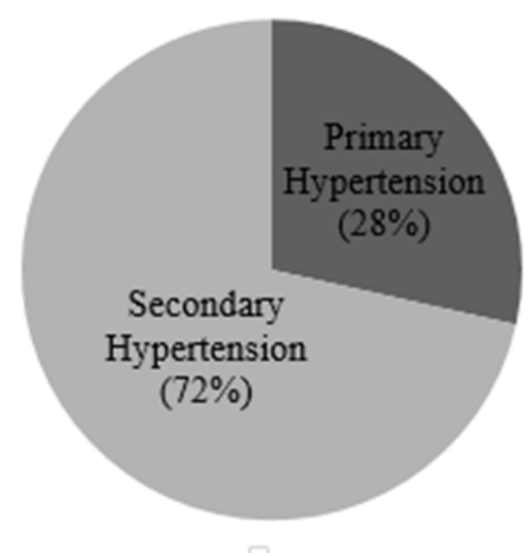

Figure 1. Percentage of primary and secondary hypertension among the adult population

Table 1 has illustrated the association between demographic risk factors and development of hypertension for developing preventive measures. The highest value for the ones suffering from secondary hypertension were aged between $15-30$ years. On the contrary, the individuals with least value belong to the ones, who are suffering from primary hypertension. There was significant association between hypertension and age of the individual ( $\mathrm{p}$-value $=$ 0.001). It has been shown that 68 male individuals showed highest value for suffering from primary hypertension. Whereas, 14 female hypertensive patients had least value for suffering from primary hypertension. The highest number of individuals that is 69 are those who suffer from secondary hypertension and are single. On the contrary, the participants with the least value belong to the ones suffering from primary hypertension and widowed, is 1 (Table 1). It has been shown that there is significant association of development of hypertension and marital status of the individuals ( $\mathrm{p}$-value $=0.001)$. Regarding level of education, the highest values was achieved for the ones suffering from secondary hypertension and were graduated $(n=53)$. Whereas, least number of participants $(n=1)$ belong to the individuals, who were suffering from primary hypertension and were uneducated. 
Table 1. Association between demographic risk factors and development of hypertension for developing preventive measures

\begin{tabular}{|c|c|c|c|c|}
\hline & \multirow{2}{*}{ Item } & \multicolumn{2}{|c|}{ Measure } & \multirow{2}{*}{ p-value } \\
\hline & & Yes & No & \\
\hline \multirow{4}{*}{ Age } & $15-30$ years & 3 & 70 & \multirow{4}{*}{0.001} \\
\hline & $31-45$ years & 10 & 19 & \\
\hline & Age $46-60$ years & 19 & 6 & \\
\hline & $61-75$ years & 7 & 4 & \\
\hline \multirow{2}{*}{ Gender } & Male & 25 & 68 & \multirow{2}{*}{0.296} \\
\hline & Female & 14 & 31 & \\
\hline \multirow{4}{*}{ Marital status } & Single & 6 & 69 & \multirow{4}{*}{0.001} \\
\hline & Married & 27 & 27 & \\
\hline & Divorced & 2 & 2 & \\
\hline & Widow & 4 & 1 & \\
\hline \multirow{6}{*}{ Level of Education } & Uneducated & 3 & 1 & \multirow{6}{*}{0.326} \\
\hline & Khalwa & 1 & 2 & \\
\hline & Primary & 9 & 9 & \\
\hline & Secondary & 5 & 14 & \\
\hline & Graduate & 19 & 70 & \\
\hline & Post-graduate & 2 & 3 & \\
\hline
\end{tabular}

Table 2 has shown the association between lifestyle related risk factors development of hypertension for developing preventive measures. The results showed that there was no association of developing hypertension with smoking $(p$-value $=0.832)$, exercise $(p$-value $=0.100)$, and intake of carbohydrates $(p$-value $=0.065)$. Whereas, there was significant association of developing hypertension with stress $(\mathrm{p}$-value $=0.010)$ and diabetes $(\mathrm{p}$-value $=0.050)$.

Table 2. Association between lifestyle related risk factors development of hypertension for developing preventive measures

\begin{tabular}{llll}
\hline Item & Measure & $\mathrm{N}$ & $\mathrm{p}$-value \\
\hline \multirow{2}{*}{ Smoking } & Yes & 36 & \multirow{2}{*}{0.832} \\
& No & 102 & \\
\hline \multirow{2}{*}{ Exercise } & Yes & 42 & \multirow{2}{*}{0.100} \\
& No & 63 & \\
\hline \multirow{2}{*}{ Stress } & Yes & 54 & \multirow{2}{*}{0.010} \\
& No & 84 & \\
\hline \multirow{2}{*}{ Diabetes } & Yes & 25 & \multirow{2}{*}{0.050} \\
& No & 113 & \\
\hline \multirow{2}{*}{ Carbohydrate food intake } & Yes & 98 & \multirow{2}{*}{0.065} \\
\hline
\end{tabular}

\section{Discussion}

Hypertension is considered as a major common health problem, especially among the developing countries because currently its prevalence is rising steadily. It can result in major drastic future complications, if adequate 
preventive and management practices are not implied. The present study has highlighted the diagnosis of hypertension among the Sudanese adult population and mainly focused on the factors that are significantly associated with the development of hypertension. The results would help in developing adequate preventive measures for management of hypertension among the adult population. A previous study conducted by Babiker et al. (2013) stated that there was increased prevalence of hypertension among the male gender, as compared to the females. Similar results were deduced by the present study showing $64 \%$ of males and $35.9 \%$ of females suffering from hypertension. Moreover, these results show clear predominant prevalence of hypertension among the male population, as compared to the female population.

The results of present study have shown significant correlation of stress and diabetes with the development of hypertension among the individuals. A similar study showed significant relationship of hypertension with male gender, obesity, family history, older age, smoking, and illiteracy (Kandasamy et al., 2018). Another important finding relation between the study conducted in Saudi Arabia and present study of Sudan; is that the prevalence of primary hypertension in Saudi Arabia was found to be 11.8\% (Kandasamy et al., 2018); whereas, the present study showed higher prevalence percentage of $28 \%$. Another study conducted by Dogan et al. (2012) showed significant association of hypertension with age, gender, diabetes Mellitus, family history of hypertension, body mass index (BMI), chronic heart disease (CHD), and level of income. On the other hand, the present study showed association of hypertension with multiple risk factors, that is age, gender, stress, and diabetes mellitus. The study failed to show the association of hypertension with family history.

It is prerequisite to identify the deficiencies in the physician's approach towards prevention, diagnosis, and management of hypertension for planning interventions targeted towards its control. The guidelines for managing hypertension mainly aim at improving the diagnosis, evaluation, treatment, and control of hypertension. The present study has shown that knowledge of and adherence to guidelines by care givers is imperative for effective hypertension control. This is important to reduce the risk of morbidity and mortality associated with the cardiovascular complications from potentially preventable complications of hypertension. A similar study conducted by Ale and Braimoh (2017) showed that diagnostic and therapeutic advances in hypertension management are not beneficial for majority of the hypertensive patients because majority of them are managed by primary care physicians. It is possible that the clues of secondary hypertension are missed by the primary care physicians by taking initial measurement of blood pressure on only one arm. The high burden of undiagnosed hypertension is contributed as a practice of not identifying the arm with high blood pressure and using it as a reference.

The prevention and management related guidelines are likely help in the evaluation of total cardiovascular risk of hypertensive individuals. Modification of some of the risk factors explained in the present study are associated with blood pressure reduction, apart from assisting in prognostication (Lemogoum et al., 2003; Chobanian et al., 2003). A study conducted in South Africa showed that $68.8 \%$ of the primary care physicians were aware of hypertension guidelines; however, only $18.2 \%$ of them were familiar with the content thereof (Parker et al., 2011). The results of present study are limited because the study uses self-administered questionnaire that might limit the varying abilities of recalling among the participants. The study has evaluated knowledge of the suffering patients; however, it does not include any opinion of their physicians to represent the actual practices.

\section{Conclusion}

The present study has diagnosed hypertension among the adults in Al-Riyadh district, Khartoum state of Sudan. The study helped in investigated the prevention and management of primary and secondary hypertension. The study showed the major risk factors that is age, marital status, stress, and diabetes to be associated with hypertension. The category of age group ranging from 46-60 years old turned out to be highly associated with hypertension. The study results have also shown that $27 / 54$ participants whom are married, were actually having hypertension. On the contrary, 54 participants were dealing with stress, among which 9 were known hypertensive. Moreover, among 25 diabetic participants, 12 were found to have hypertension. The study results recommend formation of strategies comprising of educational programs to increase awareness of this issue to community. There is need of assessment and monitoring of individuals in regard to hypertension disease. Future studies need to conduct retrospective study and obtain data from the medical records for authenticity.

\section{Acknowledgements}

The author is very thankful to all the associated personnel in any reference that contributed in/for the purpose of this research. Further, this research holds no conflict of interest and is not funded through any source. 


\section{Competing Interests Statement}

The authors declare that there are no competing or potential conflicts of interest.

\section{References}

Abebe, S. M., Berhane, Y., Worku, A., \& Getachew, A. (2015). Prevalence and associated factors of hypertension: a crossectional community-based study in Northwest Ethiopia. PloS one, 10(4), e0125210. https://doi.org/10.1371/journal.pone.0125210

Adeloye, D., \& Basquill, C. (2014). Estimating the prevalence and awareness rates of hypertension in Africa: a systematic analysis. PloS one, 9(8), e104300. https://doi.org/10.1371/journal.pone.0104300

Ahmed, A., Rahman, M., Hasan, R., Shima, S. A., Faruquee, M. H., Islam, T., \& Haque, S. E. (2014). Hypertension and associated risk factors in some selected rural areas of Bangladesh. International Journal of Research in Medical Sciences, 2(3), 925. https://doi.org/10.5455/2320-6012.ijrms20140816

Ale, O. K., \& Braimoh, R. W. (2017). Awareness of hypertension guidelines and the diagnosis and evaluation of hypertension by primary care physicians in Nigeria. Cardiovascular journal of Africa, $28(2), 72$. https://doi.org/10.5830/cvja-2016-048

Ataklte, F., Erqou, S., Kaptoge, S., Taye, B., Echouffo-Tcheugui, J. B., \& Kengne, A. P. (2015). Burden of undiagnosed hypertension in sub-saharan Africa: a systematic review and meta-analysis. Hypertension, 65(2), 291-298. https://doi.org/10.1161/hypertensionaha.114.04394

Babiker, F. A., Elkhalifa Lamia, A., \& Moukhyer, M. E. (2013). Awareness of hypertension and factors associated with uncontrolled hypertension in Sudanese adults. Cardiovascular journal of Africa, 24(6), 208. https://doi.org/10.5830/cvja-2013-035

Chobanian, A. V., Bakris, G. L., Black, H. R., Cushman, W. C., Green, L. A., Izzo Jr, J. L., \& Roccella, E. J. (2003). The seventh report of the joint national committee on prevention, detection, evaluation, and treatment of high blood pressure: the JNC 7 report. Jama, 289(19), 2560-2571. https://doi.org/10.1001/jama.289.19.2560

Doğan, N., Toprak, D., \& Demir, S. (2012). Hypertension prevalence and risk factors among adult population in Afyonkarahisar region: a cross-sectional research. Anatolian Journal of Cardiology/Anadolu Kardiyoloji Dergisi, 12(1). https://doi.org/10.5152/akd.2012.009

Dubey, M., Rastogib, S., \& Awasthic, A. (2019). Hypertension prevalence as a function of different guidelines, India. Bull World Health Organ, 97, 799-809. https://doi.org/10.2471/blt.19.234500

Duda, R. B., Anarfi, J. K., Adanu, R. M., Seffah, J., Darko, R., \& Hill, A. G. (2011). The health of the "older women" in Accra, Ghana: results of the Women's Health Study of Accra. Journal of cross-cultural gerontology, 26(3), 299-314. https://doi.org/10.1007/s10823-011-9148-8

Forouzanfar, M. H., Alexander, L., Anderson, H. R., Bachman, V. F., Biryukov, S., Brauer, M., \& Cohen, A. (2015). GBD 2013 Risk Factors Collaborators. Global, regional, and national comparative risk assessment of 79 behavioural, environmental and occupational, and metabolic risks or clusters of risks in 188 countries, 1990-2013: a systematic analysis for the Global Burden of Disease Study 2013. Lancet, 386(10010), 2287-323. https://doi.org/10.1038/sj.bdj.2015.751

Forouzanfar, M. H., Liu, P., Roth, G. A., Ng, M., Biryukov, S., Marczak, L., \& Ali, R. (2017). Global burden of hypertension and systolic blood pressure of at least 110 to $115 \mathrm{~mm} \mathrm{Hg}, 1990-2015$. Jama, 317(2), 165-182.

Fottrell, E., Ahmed, N., Shaha, S. K., Jennings, H., Kuddus, A., Morrison, J., ... \& Khan, A. A. (2018). Distribution of diabetes, hypertension and non-communicable disease risk factors among adults in rural Bangladesh: a cross-sectional survey. BMJ global health, 3(6), e000787.

James, P. A., Oparil, S., Carter, B. L., Cushman, W. C., Dennison-Himmelfarb, C., Handler, J., \& Smith, S. C. (2014). 2014 evidence-based guideline for the management of high blood pressure in adults: report from the panel members appointed to the Eighth Joint National Committee (JNC 8). Jama, 311(5), 507-520. https://doi.org/10.1001/jama.2013.284427

Johnson, H. M., Thorpe, C. T., Bartels, C. M., Schumacher, J. R., Palta, M., Pandhi, N., ... \& Smith, M. A. (2014). Undiagnosed hypertension among young adults with regular primary care use. Journal of hypertension, 32(1), 65.

Kandasamy, K., Rajagopal, S. S., Ramalingam, K., \& Krishnan, K. (2018). An Epidemiological Study of Prevalence of hypertension and Pre-hypertension and Its Associated Risk Factors in a Rural Community: a 
Home Based Screening. Journal of Pharmaceutical Sciences and Research, 10(5), 1187-1191.

Khader, Y., Batieha, A., Jaddou, H., Rawashdeh, S. I., El-Khateeb, M., Hyassat, D., ... \& Ajlouni, K. (2019). Hypertension in Jordan: Prevalence, Awareness, Control, and Its Associated Factors. International journal of hypertension, 2019.

Lasisi, A. O., Abiona, T., \& Gureje, O. (2010). Tinnitus in the elderly: Profile, correlates, and impact in the Nigerian Study of Ageing. Otolaryngology-Head and Neck Surgery, 143(4), 510-515.

Lemogoum, D., Seedat, Y. K., Mabadeje, A. F., Mendis, S., Bovet, P., Onwubere, B., \& Belhocine, M. (2003). Recommendations for prevention, diagnosis and management of hypertension and cardiovascular risk factors in sub-Saharan Africa. Journal of hypertension, 21(11), 1993-2000. https://doi.org/10.1097/00004872-200311000-00003

Lurbe, E., Agabiti-Rosei, E., Cruickshank, J. K., Dominiczak, A., Erdine, S., Hirth, A., \& Rascher, W. (2016). 2016 European Society of Hypertension guidelines for the management of high blood pressure in children $\begin{array}{llll}\text { and adolescents. Journal of hypertension, 34(10), 1887-1920. } & \text {. }\end{array}$ https://doi.org/10.1097/hjh.0000000000001039

Mendis, S. (2010). Global status report on non-communicable diseases 2010. Tech. Rep., World Health Organization, 2010. Retrieved from http://www.who.int/nmh/publications/ncd report2010/en/

Menéndez, E., Delgado, E., Fernández-Vega, F., Prieto, M. A., Bordiú, E., Calle, A., ... \& Gaztambide, S. (2016). Prevalence, diagnosis, treatment, and control of hypertension in Spain. Results of the Di@ bet. es study. Revista Española de Cardiología (English Edition), 69(6), 572-578.

Mills, K. T., Bundy, J. D., Kelly, T. N., Reed, J. E., Kearney, P. M., Reynolds, K., ... \& He, J. (2016). Global disparities of hypertension prevalence and control: a systematic analysis of population-based studies from 90 countries. Circulation, 134(6), 441-450.

Mkhize, X., Napier, C., \& Oldewage-Theron, W. (2013). The nutrition situation of free-living elderly in Umlazi township, South Africa. Health SA Gesondheid (Online), 18(1), 1-8.

Negin, J., Cumming, R., de Ramirez, S. S., Abimbola, S., \& Sachs, S. E. (2011). Risk factors for non-communicable diseases among older adults in rural Africa. Tropical Medicine \& International Health, 16(5), 640-646.

Ogah, O. S., Okpechi, I., Chukwuonye, I. I., Akinyemi, J. O., Onwubere, B. J., Falase, A. O., \& Sliwa, K. (2012). Blood pressure, prevalence of hypertension and hypertension related complications in Nigerian Africans: A review. World journal of cardiology, 4(12), 327. https://doi.org/10.4330/wjc.v4.i12.327

Oliveira-Martins, S. D., Oliveira, T., Gomes, J. J., Caramona, M., \& Cabrita, J. (2010). Factores associados à hipertensão arterial nos utentes de farmácias em Portugal. Revista de Saúde Pública, 45, 136-144.

Parker, A., Nagar, B., Thomas, G., Ntusi, N. B. A., \& Badri, M. (2011). Health practitioners' state of knowledge and challenges to effective management of hypertension at primary level. Cardiovascular journal of Africa, 22(4), 186. https://doi.org/10.5830/cvja-2010-066

Pinto, I. C., \& Martins, D. (2017). Prevalence and risk factors of arterial hypertension: A literature review. Journal of Cardiovascular Medicine and Therapeutics, 1(2), 1-7.

Salako, B. L., Ogah, O. S., Adebiyi, A. A., Adedapo, K. S., Bekibele, C. O., Oluleye, T. S., \& Okpechi, I. K. E. C. H. I. (2007). Unexpectedly high prevalence of target-organ damage in newly diagnosed Nigerians with hypertension. Cardiovascular Journal of South Africa, 18(2), 77.

Sarki, A. M., Nduka, C. U., Stranges, S., Kandala, N. B., \& Uthman, O. A. (2015). Prevalence of hypertension in low-and middle-income countries: a systematic review and meta-analysis. Medicine, 94(50).

Sayers, E. W., Barrett, T., Benson, D. A., Bolton, E., Bryant, S. H., Canese, K., \& Feolo, M. (2009). Database resources of the national center for biotechnology information. Nucleic acids research, 38(suppl_1), D5-D16. https://doi.org/10.1093/nar/gkn741

Singh, S., Shankar, R., \& Singh, G. P. (2017). Prevalence and associated risk factors of hypertension: a cross-sectional study in urban Varanasi. International journal of hypertension, 2017. https://doi.org/10.1155/2017/5491838

Tabrizi, J. S., Sadeghi-Bazargani, H., Farahbakhsh, M., Nikniaz, L., \& Nikniaz, Z. (2016). Prevalence and associated factors of prehypertension and hypertension in Iranian Population: The Lifestyle Promotion 
Project (LPP). PloS one, 11(10), e0165264. https://doi.org/10.1371/journal.pone.0165264

Tucker, K. L., Sheppard, J. P., Stevens, R., Bosworth, H. B., Bove, A., Bray, E. P., ... \& Hebert, P. (2017). Self-monitoring of blood pressure in hypertension: a systematic review and individual patient data meta-analysis. PLoS medicine, 14(9), e1002389. https://doi.org/10.1371/journal.pmed.1002389

Van Kleef, M. E., \& Spiering, W. (2017). Hypertension: Overly important but under-controlled. European journal of preventive cardiology, 24(3_suppl), 36-43. https://doi.org/10.1177/2047487317709116

\section{Copyrights}

Copyright for this article is retained by the author(s), with first publication rights granted to the journal.

This is an open-access article distributed under the terms and conditions of the Creative Commons Attribution license (http://creativecommons.org/licenses/by/4.0/). 